\title{
¿UNA LECTURA PSICOANALÍTICA DE CANALLAS? SOBRE EL PROBLEMA AUTOINMUNITARIO DE LA SOBERANÍA DEMOCRÁTICA ${ }^{1}$
}

\author{
Cristóbal Olivares Molina \\ Pontificia Universidad Católica de Chile (CONICYT) \\ Universidad Complutense de Madrid \\ crolivar@ucm.es; cjolivares@uc.cl
}

\begin{abstract}
Resumen / Abstract
Se propone la posibilidad de una lectura psicoanalítica del Canallas de Derrida. Se intentará demostrar que la condición autoinmunitaria de la soberanía democrática, aquella condición aporética que la afirma y la niega a la vez, puede ser reconsiderada desde el psicoanálisis, así como también desde la interpretación que el mismo Derrida ha hecho de los conceptos de pulsión de muerte, rodeo y compulsión de repetición en La tarjeta postal. Ahora bien, parece posible extender esta relectura del problema autoinmunitario hasta ciertas problemáticas asociadas a Lacan. En última instancia, sería posible una contribución lacaniana al problema ético-político de la autoinmunidad de la soberanía democrática planteada por Derrida.
\end{abstract}

Palabras Clave: Derrida, Freud, Lacan, democracia, autoinmunidad, rodeo, pulsión de muerte, compulsión de repetición, Umweg, détour.

\section{A PSYCHOANALYTIC READING OF ROGUES? ON THE AUTOIMMUNITARY PROBLEM OF DEMOCRATIC SOVEREIGNTY}

It is propose the possibility of a psychoanalytic reading of Derrida's Rogues. It is try to show that the autoimmune condition of democratic sovereignty, the aporetic condition that affirms and denies it at once, can be reconsidered from psychoanalysis, as well as from the interpretation that Derrida himself has made of concepts like death drive, detour and repetition compulsión in The Post Card. However, it seems possible to extend this rereading of the autoimmune problem to certain problems associated to Lacan. Ultimately, a Lacanian contribution it would be posible to the ethico-political problem of autoimmunity of democratic sovereignty raised by Derrida.

KEY WORDS: Derrida, Freud, Lacan, democracy, autoinmunity, detour, death drive, repetition compulsion, Umweg, détour.

Agradezco al profesor Andrea Potestà (PUC) por la supervisión inicial de este escrito. También agradezco a Daniela Alegría (PUC/UCM) por sus comentarios y sugerencias. 
“¿Qué puede un psicoanálisis pasado o por venir decirnos de la democracia?”

(Derrida 2005, p. 74)

\section{1) El rendimiento político del psicoanálisis en la obra tardía de Jacques Derrida}

$\overline{R A}$

Hay en el pensamiento de Jacques Derrida un rendimiento político del psicoanálisis que amerita ser explicitado con el objeto de reconsiderar algunos problemas planteados en Voyous (en adelante Canallas). Quiero demostrar que la vinculación del psicoanálisis con temas como la soberanía y el poder sobre la vida y la muerte (Cfr., "Post-scriptum" en Derrida 2001b, pp. 365-385) es solidario de una interpretación de la teoría de las pulsiones de Freud (Cfr., "Más allá del principio de placer" en 2012) que se encuentra en La tarjeta postal (Cfr., "Especular -sobre Freud" en 2001b), y que no dejará de tener efectos sobre su obra tardía. Ahora bien, en los dos ensayos que componen Canallas aparece el término autoinmunidad para explicar la capacidad que tiene la democracia para exponerse ya sea a una libertad sin límites como al peligro de su propia destrucción. Al respecto sostendré, en primer lugar, que a través del psicoanálisis freudiano puede replantearse la problemática "ético-política" ${ }^{2}$ de Derrida en torno a la democracia y su "auto-inmunidad"3 (concepto, éste último, abierto a otras variantes como el de "lógica auto-inmunitaria"4, "proceso auto-inmunitario", "suicidio auto-

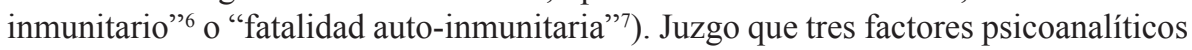
(el rodeo, la pulsión de muerte y la compulsión de repetición) sirven, a la luz de la crítica derrideana, en la reconsideración del problema de lo autoinmunitario. Quiero reforzar este ejercicio de interpretación mostrando brevemente aspectos estratégicos de la lectura de la teoría de las pulsiones llevada a cabo por el mismo Derrida en La tarjeta postal (Cfr., "Especular-sobre Freud" en 2001b), especialmente en lo referente al movimiento que constituye la economía de las pulsiones del organismo vivo en analogía con el movimiento autoinmunitario de la soberanía democrática. En segundo lugar, quiero trazar las coordenadas a partir de las cuales, en un trabajo futuro sobre las relaciones entre Derrida y Lacan, poder desarrollar la idea según la cual la esencia del problema autoinmunitario radica en la naturaleza paradójica que deseo ${ }^{8}$ y goce expresan

Cfr., Ferraris 2006, p. 109 y Derrida 2005, p. 58.

Véase Derrida 2005, p. 35.

Véase Derrida 2005, p. 55.

Véase Derrida 2005, p. 54.

Véase Derrida 2005, p. 52.

Véase Derrida 2005, p. 56.

Habría que advertir que en Freud no hay una articulación de Wunsch (deseo) y Genuss (goce) tal como lo ha hecho Jacques Lacan con désir y jouissance, articulación de la que sin duda Derrida se vale para caracterizar la dinámica de lo político y de lo democrático en esa breve cita que encontramos en Canallas (Cfr., 2005, pp. 32-33). Tal como señala Néstor A. 
en el marco de la soberanía democrática: "No debemos disociar nunca la cuestión del deseo [désir] y del goce [jouissance], cuando se trata de lo político, especialmente de lo democrático, del goce consciente o inconsciente, del cálculo o de lo incalculable, a los cuales dan lugar el deseo y el goce" (Derrida 2005, pp. 32-33). Considero que, en última instancia, el esbozo de una perspectiva lacaniana podría ilustrarnos acerca de la centralidad política o ético-política que tanto deseo como goce pueden llegar a cumplir en la problemática derrideana de la democracia.

\section{2) La soberanía democrática y la repetición como ley de su autoinmunidad}

En el contexto de Canallas, por autoinmunidad Derrida comprende el efecto de una "ley" que subyace a la democracia y la soberanía. Ahora bien, esta ley tiene la estructura de una "rueda", "rotación", "circularidad"; términos que pueden ser reconducidos metonímicamente al de "repetición". Derrida señala que lo esencial de la democracia está asociado a este efecto de repetición o circularidad: "Parece difícil pensar el deseo o la nominación de algún espacio democrático sin lo que se denominaba en latín una rota, sin la rotación o la rodadura, sin la redondez o la rotundidad giratoria del redondel que gira en redondo, sin la circularidad" (2005, p. 27). Piénsese en el fenómeno de las elecciones, propio de las democracia modernas ${ }^{10}$. Al contrario de otros sistemas no-

Braunstein en su espléndido estudio El goce. Un concepto lacaniano (2013), para Freud, el goce "nunca fue otra cosa que un vocablo de la lengua, que no hizo de él un concepto de su teoría" (Braunstein 2013, p. 14). Braunstein afirma que "[1]a significación vulgar convierte en sinónimos el goce y el placer" (Ibíd.), pero la significación lacaniana "los enfrenta, y hace del goce ora un exceso intolerable de placer, ora una manifestación del cuerpo más próxima a la tensión extrema, al dolor y al sufrimiento." (Ibíd.). Sin embargo, para Lacan no deja de haber una teoría implícita del deseo y del goce en el mismo Freud. Es Lacan quien en La ética del psicoanálisis señalaba que "el goce se presenta no pura y simplemente como la satisfacción de una necesidad sino como la satisfacción de una pulsión" (Cfr., Lacan 2011); cuestión que tal como subraya Braunstein, se trata precisamente de la satisfacción de la "pulsión de muerte" freudiana (Cfr., 2013, p. 62). Y agrega: "Si el goce tiene que ver con la pulsión es en la medida en que la pulsión deja un saldo de insatisfacción que anima a la repetición" (Ibíd., p. 65). De hecho, en la tematización lacaniana, el goce también se vuelve fundamento de la compulsión de repetición (Ibíd.: 60). Sin poder desarrollar con mayor extensión estos conceptos, propios de una recepción francesa del psicoanálisis, en una investigación futura quisiera desarrollar con mayor profundidad el sentido de los conceptos de goce y deseo, y su función en el marco de la soberanía democrática. Para el concepto de jouissance y désir en psicoanálisis véase: i) Lacan (2008) y ii) Lacan (2011). Para estudios específicos sobre el goce en Lacan: i) Miller (1999) y ii) Braunstein (2013). Véase Derrida, Jacques, "La rueda libre" en Canallas (2005).

10 Subrayo la relación de las elecciones de los cargos en las democracias modernas para no confundirlas con el fenómeno del kleroterion o sorteo de los cargos en la Asamblea de Atenas. Como explica Rafael del Águila, la especificidad de la democracia griega es rotación azarosa: "El centro de poder y de decisión del sistema político ateniense era, de hecho, la 
democráticos donde el ejercicio del poder no es sometido a sufragio, la idea democrática es que la soberanía debe ir rotando sucesivamente entre la multitud de ciudadanos, para evitar el peligro que implica la perpetuación no-democrática en el poder. La soberanía democrática se caracteriza por esta ley circular:

la democracia sería eso, a saber: una fuerza ( $k r a t o s)$, una fuerza determinada como autoridad soberana (kyrios o kyros, poder de decidir, de zanjar, de prevalecer, de dar-cuenta-de y de otorgar fuerza de ley, kyroo), por consiguiente, el poder y la ipseidad del pueblo (demos). Dicha soberanía es una circularidad, incluso una esfericidad. La soberanía es redonda, un redondeo. Esa rotación circular o esférica, el tornar de ese re-torno sobre sí puede tomar ya sea la forma alternativa del por turno, de a cada cual su turno, turnándose (Derrida 2005, p. 30).

No olvidemos distinguir lo democrático de lo soberano propiamente tal ${ }^{11}$, y el tipo de repetición que rige en cada uno. Por un lado, lo democrático ${ }^{12}$ a secas está asociado a

Asamblea (ekklesia) de todos los ciudadanos, que se reunían al menos cuarenta veces al año y votaban sobre leyes, finanzas, impuestos, relaciones exteriores, orden público (...) [no obstante] Prácticamente todos los puestos ejecutivos que surgían de esta Asamblea no eran objeto de elección sino de sorteo entre los ciudadanos (...) con la excepción de algunos puestos característicos (por ejemplo, de los jefes militares-strategoi-, etc.)" (2013, p. 16). Vale la pena mencionar que no es del todo evidente la solidaridad entre democracia y soberanía. La democracia no puede ser reducida necesariamente a una teoría del Estado. Puede estar asociada a la praxis política pero no necesariamente al gobierno, administración y repartición del poder soberano. Por ejemplo, en Elogio de lo común, Antonio Negri opone una "democracia absoluta" de la multitud a la tradicional "democracia constitucional". Véase 2012, p. 127.

12 Hay que distinguir conceptualmente la noción de soberanía democrática de la noción de "democracia por venir" que introduce Derrida. El sintagma "democracia por venir" introduce una suerte de diferencia irreductible en el seno de la noción tradicional de democracia. La democracia por venir en Derrida no es una teoría del gobierno que defina cómo es o cómo debe ser un régimen democrático en el presente. La democracia por venir tampoco es un nombre que equivalga a un proyecto utópico-teleológico que determine un programa de acciones y metas para el futuro. "Democracia por venir" es una noción deudora de elaboraciones conceptuales paralelas de Derrida (en torno a la justicia y al derecho, a la hospitalidad, al acontecimiento, en torno a la experiencia de lo imposible, entre otras), e indica la urgencia permanente de mayor democracia, de que siempre es posible más democracia. El sintagma democracia por venir en Derrida también indica, en parte, que la democracia esperada siempre va más allá la democracia presente, en el sentido de que los Estados no son la democracia definitiva, no son ni serán la fórmula acabada y presente de la democracia, ni siquiera la garantía absoluta de una vida plenamente democrática. Democracia por venir para Derrida indica una exigencia incondicional para la política y el pensamiento de la política: que la democracia siempre es y debe ser perfectible. Me parece que sería posible problematizar la relación del psicoanálisis freudiano y la interpretación derrideana del psicoanálisis con la cuestión de la "democracia por venir". Por ejemplo, en Estados de ánimo del psicoanálisis Derrida se pregunta sobre la posibilidad de un psicoanálisis que sea capaz de pensar un más allá de la vida y la pulsión de muerte, y en política, un más allá de la soberanía y la 
una repetición de la alternancia, lo que Derrida llama el "por turno, a cada cual su turno, turnándose" y que fácilmente podemos asociar al sufragio. Por otro lado, la soberanía a secas siempre está asociada a la repetición de lo mismo, repetición de la ipseidad ${ }^{13}$, sea o no del pueblo, sea del rey, sea del dictador, etc. Ahora bien, lo que Derrida llama la "ley" de la repetición -o de la circularidad- que subyace a la soberanía democrática, y que está detrás del efecto autoinmunitario, no es simplemente la repetición de la alternancia ni la repetición de la ipseidad. La característica esencial de la ley de repetición del fenómeno autoinmunitario, como veremos, implica una especie de "lógica" aporética ${ }^{14}$, irresoluble, ya que puede y no puede desencadenar efectos de ipseidad, puede y no puede desencadenar efectos de alternancia, puede y no puede desencadenar efectos libertarios, puede y no puede desencadenar efectos de fuerza y perversión. Esto que he mencionado como "aporético" bien puede ser entendido como aquello que Derrida ha llamado el movimiento "elíptico" o "Elleipsis"15. La elipsis implica una repetición cuyo eje siempre se desplaza, por lo que nunca lo repetido es lo mismo:

Una vez repetida, la misma línea no es ya exactamente la misma, ni el bucle tiene ya exactamente el mismo centro (...) El retorno de lo mismo sólo se altera por volver a lo mismo. La pura repetición, aunque no cambie ni una cosa ni un signo, contiene una potencia ilimitada de perversión y de subversión" (Derrida 2012a, p. 404).

Como veremos, en Canallas de Derrida, el efecto autoinmunitario surge de la dimensión elíptica de la ley de repetición que subyace a la soberanía democrática.

crueldad, es decir, más allá del poder sobre la vida y la muerte: “¿podemos pensar esto aparentemente imposible (...) un más allá de la pulsión de muerte o de dominio soberano, por lo tanto el más allá de una crueldad, un más allá que nada tendría que ver ni con las pulsiones ni con los principios?" (Derrida 2001a, p. 14). Se trataría de un psicoanálisis ligado al pensamiento de lo que Derrida llama la "sobre-vida" o la "súper-vivencia". Este pensamiento debería interrumpir el circuito económico de la oposición entre vida y muerte a partir del cual se constituye la soberanía.

13 A "ipseidad", Derrida asocia la autodeterminación soberana que se funda en un retorno (circular, repetitivo) sobre sí mismo: auto-determinación, es decir, la capacidad de darse a sí mismo y desde sí mismo la propia ley. Véase Derrida (2005, p. 28).

14 La figura de la aporía se presenta como un conflicto imposible de resolver, al mismo tiempo que ineludible para el pensamiento. Para un estudio exhaustivo de las figuras de la aporía en Derrida véase "La experiencia de la aporía" y "Estructura aporética de la deconstrucción" en Contreras (2010).

15 Véase "Elipsis" en La escritura y la diferencia (Derrida 2012a). 


\section{3) Paréntesis: la autoinmunidad como metáfora celular}

El concepto de autoinmunidad es una metáfora que tiene su origen en un proceso celular mediante el cual el sistema inmunológico del organismo, en vez de protegerse contra una célula externa (antígeno), responde contra sus propias células, que no reconoce como propias sino como externos. El resultado es que en el proceso autoinmunitario, a diferencia del proceso inmunitario, el organismo se hace daño a sí mismo, exponiéndose a su propia posibilidad de destrucción. Un caso ejemplar es el SIDA. Cuando un organismo vivo está infectado por el virus del SIDA, éste responde autoinmunitariamente contra sus linfocitos-T, a los que confunde con parásitos externos, pero que son los encargados de defender al organismo de ciertas infecciones realmente externas. De modo que la respuesta autoinmunitaria contra los linfocitos-T da por resultado que el organismo vivo se debilite internamente, y se vaya quedando sin defensas contra las infecciones, lo que resulta finalmente en la muerte del mismo.

Derrida extrapola la metáfora celular a varios fenómenos vinculados a la democracia ${ }^{16}$ : i) La suspensión soberana de los resultados de las elecciones democráticas de Argelia de 1992, que habían dado por ganadores a la lista de los fundamentalistas islámicos (Frente Islámico de Salvación), con el objetivo de salvar la democracia, ii) el acceso democrático al poder por parte de los nazis en Alemania, a partir de lo cual ejercieron el gobierno totalitario que suprimió el sistema democrático, iii) la suspensión de libertades civiles (mediante la Patriot Act, votada por el Congreso) en Estados Unidos tras el Atentado a las Torres Gemelas, con el objetivo de proteger la soberanía democrática de ese país contra los ataques del terrorismo islámico, etc. Teniendo en cuenta lo anterior, la relación entre democracia y autoinmunidad, para Derrida está relacionada con aquella "ley" de repetición o rotación (repetición o rotación de rutinas y procedimientos legislativos, administrativos y judiciales, por ejemplo) que en uno de sus consecutivos giros, al modo de elipsis, puede permitir que se produzca un efecto perverso a partir de esa misma estructura que la hace posible. Así como el organismo vivo puede pervertir el proceso de inmunidad contra sí mismo, dándose la muerte, la democracia puede permitir fuera de todo cálculo, por su misma naturaleza elíptica, que surja un poder antidemocrático que la niegue. En este sentido es que para Derrida el problema de la "auto-inmunidad" del organismo refleja una potencia autodestructiva siempre latente en la soberanía democrática ${ }^{17}$ que exige, en contrapartida, análisis vigilante y responsabilidad ${ }^{18}$.

16 Véase "Lo otro de la democracia, el por turno: alternativa y alternancia" (Derrida 2005).

17 Véase Derrida (2005, p. 134), Derrida (2010), Derrida (2011).

18 Al final de Canallas, Derrida desarrolla la idea, a partir de una lectura de Husserl, de cierta dificultad de la razón asociada a la autoinmunidad, en el sentido de que la razón también compartiría esta estructura paradójica, surgida en primera instancia de la metáfora biológico-celular. Según Derrida, la razón es inseparable de su propia crisis, es decir, de la posibilidad de extraviarse su misión ilustrada. La crisis inherente a la razón la divide entre el pensamiento de una exigencia incondicional e intransigente y de una determinación 
Ahora bien, sería un error reducir la autoinmunidad solo a una metáfora biológico-celular aplicable al dominio de lo político. Para Derrida, la autoinmunidad es un proceso que debe ser pensado de modo anterior a la separación entre vida orgánica y vida política, vida animal o vida humana, naturaleza o cultura, anterior, en definitiva, a la distinción entre physis, bios, zoé y sus opuestos tekhné, nómos, thesis. La autoinmunidad viene a ser aquél término que permite pensar la juntura que subyace a estas oposiciones, especialmente entre vida y muerte. Es en este sentido que el mero dato biológico-celular resulta insuficiente para comprender la profundidad del concepto $\mathrm{y}$, tal como propongo, sea necesario recurrir a las fuentes psicoanalíticas que, de hecho, operan en el pensamiento derrideano. Como veremos, el rodeo psicoanalítico (Umweg, détour) es una instancia que nos permite pensar la distribución oposicional entre la vida y la muerte, el placer y el displacer, lo orgánico y lo político, lo democrático y lo no-democrático.

\section{4) Autoinmunidad y violencia}

Derrida ha subrayado que la soberanía siempre está implicada en la lógica circular de la repetición, del "re-torno sobre sí". Ahora bien, para el filósofo argelino, la repetición como tal, la circularidad o el "re-torno sobre sí", es un fenómeno solidario de la violencia: "En la tortura, siempre hay una rueda. La tortura pone siempre en funcionamiento la violencia circundante y la repetición insistente, el encarnizamiento, el torno y el retorno de algún círculo" (2005, p. 25). ¿Cómo es que la circularidad de la soberanía democrática puede devenir "violencia circundante", a saber, perversión autoinmunitaria? Como si se tratara de una rueda de la fortuna, ese movimiento circular, repetitivo y rotundo de la soberanía democrática, en una de sus elipsis -recordemos la Elleipsis- bien puede producir resultados negativos que signifiquen el "suicidio" de la ipseidad en repetición: "Quizás formalizaremos más adelante, siempre con la figura de esa rueda, de esa rueda que rota sobre sí misma, de una torna más, de la redondez del turno y del torno, así como de ese retorno sobre sí, la ley de una aterradora auto-inmunidad suicida" (2005, p. 35).

calculable y controlada. Frente a esta crisis sin solución no puede hacerse otra cosa que asumir una responsabilidad, en cierto modo, análoga a la responsabilidad política que, según Derrida, hay que asumir por la democracia a pesar de su exposición permanente al peligro de su corrupción autoinmunitaria: "la razón transita y transige entre, por una parte, la exigencia razonada del cálculo o de la condicionalidad y, por otra parte, la exigencia intransigente, es decir, no negociable, de lo incalculable incondicional. Esta exigencia intratable da cuenta y debe dar cuenta de todo. (...) La responsabilidad de la razón, de la experiencia que consiste en conservar la razón (...) yo la situaría justamente en la mayor dificultad, en verdad, en la aporía auto-inmunitaria de esa transacción imposible entre lo condicional y lo incondicional, el cálculo y lo incalculable. Transacción sin ninguna regla previa, sin garantía absoluta. No hay ninguna profilaxis segura contra lo autoinmunitario", en Derrida (2005, pp. 180-181). La cuestión de la responsabilidad es central en la segunda parte de Canallas y será retomada brevemente en la conclusión de este trabajo. 
Pero no siempre el resultado es negativo. Como señala Julián Santos en Cuestiones de marco, a propósito de la problemática de Canallas: "Esa vuelta de la democracia sobre sí, esa vuelta sin vuelta, sin cierre del círculo, sobre lo que viene, hace que la democracia se invente y se revele (se rebele también) en cada clamor de justicia" (Santos 2014, p. 328). Y así como la repetición es capaz de efectos perversos, la ley repetitiva de la autoinmunidad también es condición de posibilidad de efectos afirmativos para la vida democrática, por ejemplo, i) la auto-crítica: "el derecho a la autocrítica, otra forma de la auto-inmunidad como posibilidad esencial, original, constitutiva y específica de lo democrático" (2005: 94), ii) la libertad de expresión o el derecho a decirlo todo en público: "La democracia, es el único sistema, el único paradigma constitucional en el que, en principio, se tiene o se arroga uno el derecho a criticarlo todo públicamente, incluida la idea de democracia" (2005, p. 111). ¿Quién podría imaginar un régimen totalitario, teocrático o dictatorial, donde el derecho a manifestar la inconformidad de modo radical no sea objeto de persecución? ¿O quién podría reconocer como democrático un régimen donde la literatura sea censurada o la oposición declarada fuera de la ley? La autoinmunidad es condición de posibilidad de ambas a la vez. En consecuencia, es importante subrayar que para Derrida "la auto-inmunidad no es un mal absoluto" (2005, p. 182), aunque a veces parezca confundirse con el mal. Inclusive habría que decir que esa autoinmunidad es también condición de posibilidad de la justicia, entendida esta última como respuesta y responsabilidad "ante el otro, ante cada otro, ante cualquier otro" (Santos 2014, p. 327); precisamente, ante ese otro por el cual la soberanía democrática se inmuniza a sí misma (el inmigrante, el marginal, el disidente, pero también el fundamentalista religioso, el terrorista). Más que una oposición entre efectos afirmativos y efectos negativos, el concepto de autoinmunidad nos reporta más bien la condición ambivalente que cruza toda la vida democrática. Condición que, por cierto, no puede ser suprimida por ninguna constitución o forma de organización soberana, pero que tampoco puede ser subsanada por la conjetura de una "democracia absoluta" purificada de los males de la "democracia constitucional" (Cfr., Negri \& Casarino 2012, p. 127). "La ambigüedad de la democracia es estructural y se pone por obra en sus mismas estrategias de conservación" (Santos 2014, p. 326), subraya Santos al respecto. Ahora bien, propongo que nos introduzcamos en el concepto de autoinmunidad a partir del problema que presenta la pulsión de muerte, la compulsión de repetición y el rodeo en el psicoanálisis, ya que estos conceptos, al dar cuenta de la capacidad negativa o autodestructiva del viviente, ilustran una cualidad paradojal estrechamente solidaria de la aporía que la democracia posee en Derrida.

\section{5) Autoinmunidad y psicoanálisis}

La temática de la autoinmunidad nos reenvía a problemas íntimamente solidarios del psicoanálisis freudiano. En Canallas, Derrida declara: "Sin auto-inmunidad -lo digo de una forma un tanto sentenciosa para ir deprisa-, no habría psicoanálisis ni aquello que el psicoanálisis denomina $<<$ inconsciente $>>$. O < <ulsión de muerte $>>$ " (2005, p. 75). Como hemos visto, hay lo autoinmunitario, dado en cierto contexto o estructura, pero 
que, tal como señala la cita, es extensible al campo freudiano. En primera instancia, la derrideana autoinmunidad nos permitiría pensar todo el tema freudiano de lo inconsciente y de la pulsión de muerte, como si se tratara de su condición de posibilidad. Por ejemplo, a través del pensamiento de la autoinmunidad podríamos concebir el movimiento elíptico mediante el cual el ser viviente puede hacer de la autodestrucción (pulsión de muerte) ${ }^{19}$ el motivo de su propia finalidad; motivo inconsciente, por cierto, ya que tal como en la metáfora biológico-celular, el motivo auto-destructivo nunca llega a ser presente a la conciencia del ser viviente, que, en efecto, imagina defenderse de una amenaza realmente exterior. Ahora bien, con el objeto de tornar explícito el alcance político que el psicoanálisis tiene en Derrida y sobre Derrida, yo propongo realizar un camino de interpretación inversa: pensar la tematización de la autoinmunidad, tardía en la obra del pensador argelino, a partir del concepto de "pulsión de muerte" (Todestrieb), tal como Derrida trabajó este concepto freudiano en "Especular-sobre Freud": poniendo énfasis en el "rodeo" o "desvío" (Umweg) como la instancia constituyente de la pulsión de muerte. Considero que la estrategia de lectura que propongo puede justificarse tanto desde una perspectiva historiográfica como teórica. Por un lado, la conceptualización de la pulsión de muerte en Freud proviene de 1920 en "Más allá del principio de placer", y Derrida no articula este concepto freudiano a su estrategia hasta 1980, cuando publica una interpretación del mismo en el ensayo "Especular -sobre Freud" al interior del libro La tarjeta postal. La elaboración explícita de la temática de la autoinmunidad no aparece sino entre los 90 y comienzos de la década del $2000^{20}$. Adicionalmente, la conceptualización de un ser viviente que es capaz de hacerse daño a sí mismo y alucinar su causa como exterior y no como propia, cuyo esquema sea extrapolable al análisis de la sociedad (la soberanía democrática, en particular), tal como Derrida lo hace en Canallas, ya era planteado por el pensamiento freudiano, lo que apoya la dirección de mi hipótesis de lectura. Desde "Más allá del principio de placer" hasta "Malestar en la cultura", de 1930, Freud analiza las peligrosas tendencias que genera el progreso de la cultura en el cuerpo sociall ${ }^{21}$ : paradójicamente, la cultura es la que produce resistencias contra la cultura, del mismo modo que para Derrida la democracia es capaz de generar resistencias contra la democracia ${ }^{22}$. También es en el pensamiento freudiano donde

19 Para un estudio exhaustivo sobre el concepto de pulsión de muerte en Freud, Ferenczi, Klein, Bion, Winnicott y Lacan, véase Green (2014).

20 Véase i) Derrida (2003), ii) Derrida (2005) y iii) Borradori (2003).

21 La cultura, entendida como la obra realizada por el vínculo social, produce sufrimiento en el hombre, lo que según Freud va a producir el efecto paradójico de "denegación cultural", es decir, hostilidad hacia la cultura y el vínculo social, en la medida en que la cultura socava el sentimiento de placer en el hombre. Véase Freud (2011, p. 96).

22 Un ejemplo para todo el problema que propongo analizar teóricamente puede ser el atentado contra la revista Charlie Hebdo el 7 de enero del 2015 en París. El caso es paradigmático: por un lado, a partir de ciertas condiciones autoinmunitarias que permite la libertad de expresión en Francia, Charlie Hebdo hace un uso conscientemente irresponsable de las ilustraciones gráficas para ejercer públicamente su "derecho a decirlo todo" a través de sátiras políticas que en ocasiones se burlan de las propias comunidades (nacionales o extranjeras) 
encontramos esbozada esta dinámica de autoagresión (pulsión de muerte) asociada a una "compulsión de repetición" ${ }^{23}$, análogamente a como Derrida está pensando la "violencia circundante" de la autoinmunidad y la ley circular que la presupone. Ahora bien, la clave de esta dinámica autoinmunitaria se puede encontrar en lo que Freud llamó el rodeo (Umweg). Sostengo que la ley de repetición (o ley circular, entre otros nombres) que presupone la autoinmunidad derrideana obedece necesariamente al movimiento elíptico del rodeo o desvío, tal como el psicoanálisis nos permite pensar este movimiento del rodeo en el contexto de la vida pulsional.

\section{6) Compulsión de repetición (Wiederholungszwang) y pulsión de muerte (Todestrieb)}

La pulsión de muerte (Todestrieb) es un concepto que Freud introdujo en "Más allá del principio de placer", y está estrictamente asociado a la observación del fenómeno clínico de la "compulsión de repetición"24. La compulsión de repetición (Wiederholungszwang) es un comportamiento que Freud dice haber visto en múltiples ocasiones, destacando

que componen la República francesa, y por otro lado, un grupo minoritario de ideología radical decide responder violentamente contra un símbolo del país en el que ellos viven pero del que se sienten, con no pocas razones, excluidos. Podría pensarse el atentado terrorista como una consecuencia perversa del ejercicio autoinmunitario de la libertad de expresión, producido por el ejercicio irresponsable del "derecho a decirlo todo" en democracia, esta vez contra las minorías marginales de la República francesa. En este sentido, el atentado terrorista, y todas las condiciones que hicieron posible su acontecimiento, son índices de un contemporáneo "malestar en la cultura" (francesa, europea, occidental, cristiana, mundial). De un malestar democrático de carácter autoinmunitario. Habría que pensar hasta qué punto la masacre de la noche del 13 de noviembre de 2015 en París se deja o no pensar a través de la lógica autoinmunitaria de la democracia. François Hollande, en una de sus declaraciones, explicaba que "[n]os atacan porque Francia es un país de libertad y derechos humanos" al mismo tiempo que anunciaba los proyectos de reforma constitucional para la lucha contra el terrorisme de guerre que algunos ya han comparado con lo que fue la Patriot Act de la era de George W. Bush. ¿Vaticinaba el Presidente Hollande el comienzo de una nueva ola autoinmunitaria?

23 Efectivamente, Freud en El malestar en la cultura identifica el orden político, social y cultural con la compulsión de repetición: "El orden es una suerte de compulsión de repetición que, una vez instituida, decide cuándo, dónde y cómo algo debe ser hecho, ahorrando así vacilación y dudas en todos los casos idénticos. Es imposible desconocer los beneficios del orden; posibilita al ser humano el mejor aprovechamiento del espacio y el tiempo, a la par que preserva sus fuerzas psíquicas"; en Freud (2011, p. 92).

24 Derrida se ocupará ampliamente de la pulsión de muerte a partir de la publicación de $L a$ tarjeta postal en 1980. Sugiero leer el capítulo "Pulsiones de vida y muerte: una lectura desde la inscripcionalidad" de la profesora Rosaura Martínez Ruiz (2013). Se encuentra ahí una original interpretación de la problemática de la pulsión de muerte en Freud y Derrida que lamentablemente aquí no será desarrollada. 
especialmente dos. En un caso, en los juegos infantiles, especialmente en el juego infantil Fort-Da (Cfr., Freud 2012a, pp. 14-17). En este juego infantil, Freud ve que el niño se divierte con sus juguetes sometiéndolos a una constante aparición/desaparición: el niño arroja fuera de su vista los juguetes (Fort), señalando que ya no están, luego los recupera y los coloca frente a su vista $(D a)$, señalando que están junto a él. Sin poder extenderme mayormente sobre la descripción de este juego, Freud concluye que el niño, cada vez que ve salir a su madre de la casa, a través del juego Fort-Da escenifica el abandono de la madre, hecho displacentero en su origen. Pero el niño se divierte repitiendo compulsivamente la escena de ese abandono. La compulsión de repetición en este caso llama la atención sobre aquél comportamiento del niño, que gira en torno a un hecho penoso. Pero el caso más clarificador para Freud se da en la experiencia clínica, cuando el paciente presenta lo que el psicoanalista llama "neurosis de transferencia": "los neuróticos repiten en la transferencia todas estas ocasiones indeseadas y estas situaciones afectivas dolorosas, reanimándolas con gran habilidad" (Freud 2012, p. 21). Repiten, una y otra vez, lo que los hace sufrir en la vida diaria, en la transferencia (analista-analizante) de la experiencia analítica. Pero tal fenómeno de compulsión de repetición para Freud va más allá de los neuróticos:

Se conocen individuos en quienes toda relación humana lleva a idéntico desenlace: benefactores cuyos protegidos (por disímiles que sean en los demás) se muestran ingratos pasado cierto tiempo, y entonces parecen destinados a apurar entera la amargura de la ingratitud; hombres en quienes toda amistad termina con la traición del amigo; otros que en su vida repiten incontables veces el acto de elevar a una persona a la condición de eminente autoridad para sí mismos o aun para el público, y tras el lapso señalado la destronan para sustituirla por una nueva; amantes cuya relación tierna con la mujer recorre siempre las mismas fases y desemboca en idéntico final, etc. (Freud 2012, pp. 21-22).

Freud concluirá que el origen de estas compulsiones de repetición, que siempre son repeticiones de actos que producen sensaciones displacenteras, es precisamente la pulsión de muerte.

Freud define las pulsiones, en un sentido muy general, como "representantes de todas las fuerzas eficaces que provienen del interior del cuerpo y se trasfieren al aparato anímico" (2012, p. 34). La pulsión, entonces, se ubica entre lo corporal y lo anímico, mediando entre lo uno y lo otro. La pulsión en general todavía no se define como de vida o de muerte, sino que, ante todo, se define en relación con los procesos primarios ${ }^{25}$

25 La diferencia entre procesos primarios y secundarios radica en la represión. Es por efecto de la represión, en el contexto del desarrollo del aparato psíquico, que se distribuyen los procesos psíquicos entre aquellos que permanecen conscientes y los que permanecen inconscientes. En la medida en que Freud comprende lo inconsciente como sustrato originario del aparato psíquico, llama a este "primario", en cambio, a la conciencia, en la medida en que es derivada de la represión de lo inconsciente, la llama "secundaria". Véase Freud (2012, p. 34). 
(ámbito de lo inconsciente) y los procesos secundarios (ámbito de lo consciente) del aparato psíquico. Ahora bien, de modo más específico, la pulsión de muerte pertenece al ámbito del "proceso psíquico primario", por lo que su actividad, según Freud, pasa totalmente desapercibida en la vida anímica, ya que actúa en las profundidades de lo inconsciente. Por otro lado, la pulsión de vida en gran parte, aunque no en su totalidad, forma parte del "proceso psíquico secundario", y su actividad puede ser consciente. Las sensaciones de placer y displacer son indicios de esta pulsión de vida, definidas por Freud como "cantidades de excitación presentes en la vida anímica", que pueden aumentar o disminuir en el tiempo: "el factor decisivo respecto de la sensación es, probablemente, la medida del incremento o reducción en un periodo de tiempo" (2012, p. 8). Precisamente porque se puede determinar su economía ${ }^{26}$ (mayor o menor cantidad de excitación) en el contexto del tiempo, es que el ámbito de la pulsión de vida, aunque no en su totalidad, forma parte del proceso secundario y es, por lo tanto, evidente para el observador clínico. De hecho, Freud puede determinar, a partir de la economía de la pulsión de vida, dos principios a priori de la vida anímica: el principio del placer y el principio de realidad. Por el contrario, la pulsión de muerte, en la medida en que actúa en el proceso psíquico primario, no es susceptible de una economía que pueda medirla ni del establecimiento de algún principio que pueda legislar su circulación: "los procesos anímicos inconscientes son en sí $<<$ atemporales $>>$. Esto significa, en primer término, que no se ordenaron temporalmente, que el tiempo no altera nada en ellos, que no puede aportárseles representación del tiempo" (2012, p. 28). A diferencia de la ley de repetición que rige sobre la autoinmunidad, para Freud la compulsión de repetición no es ley que impere sobre la pulsión de muerte, sino que la compulsión de repetición es efecto de la pulsión de muerte. La pulsión de muerte, en sí, no es evidente, y la única forma de acceder a ella es a través de la interpretación psicoanalítica de comportamientos compulsivos, lo que Freud llama "exteriorizaciones de la compulsión de repetición".

Tendría que volver a definirse con mayor exactitud, por un lado, los principios de placer y realidad, y por otro, la compulsión de repetición. Freud define el principio del placer como un principio de constancia de la cantidad de excitación. El principio del placer busca hacer perdurar la cantidad de excitación durante la mayor cantidad de tiempo posible o, en su defecto, evitar a toda costa el displacer por la mayor cantidad de tiempo posible. Para el organismo vivo la excesiva duración del principio del placer puede ser peligrosa, ya que expone al organismo a los peligros del mundo exterior, por lo que este principio requiere de otro principio regulador, que Freud llama "principio de realidad”. Este principio de realidad pone límite a la economía del principio del placer, a través de un rodeo (Umweg) o aplazamiento (Aufschub), con el objetivo de posibilitar

26 Recordemos que la aproximación metodológica que Freud declara utilizar en "Más allá del principio de placer" es el "punto de vista económico" (el aparato psíquico como circulación y distribución de energía excitatoria o pulsional, cuantificable según su aumento o disminución), distinto del punto de vista tópico (Primera tópica: el aparato psíquico como Inconsciente, Preconsciente y Consciente. Segunda tópica: el aparato psíquico como Ello, Yo, Superyó). 
que el organismo vivo pueda recomenzar la tendencia del placer en el futuro ${ }^{27}$. El principio de realidad es capaz de poner límite al principio del placer porque se trata de un proceso psíquico totalmente secundario, es decir, consciente. En cambio, el principio del placer es más bien primario, es decir, su origen es inconsciente, aunque no en su totalidad, ya que, según Freud, podemos medir su economía, podemos ser conscientes, en muchas ocasiones, de lo que nos causa sensaciones de placer y displacer.

Ahora bien, esto presenta algunas dificultades, ya que puede llegar a confundirse el principio del placer con la pulsión de muerte, en la medida en que ambas están conectadas al proceso psíquico primario, es decir, tienen origen inconsciente. Sin embargo, habíamos asociado el principio del placer al principio de realidad en el contexto de la pulsión de vida, en cambio, aislado de la pulsión de muerte, como una pulsión separada. En rigor, esta dificultad tiene que ver con la naturaleza dual del organismo vivo. Dice Freud que La meta de toda vida es la muerte (...) Lo inanimado estuvo ahí antes que lo vivo (2012, p. 38). Dice Freud que el origen de la vida yace en lo inanimado. La muerte como meta de la vida es el retorno de la vida a su estado inanimado originario, por lo que la pulsión de muerte es la fuerza interna de la vida que persiste hacerla cumplir su retorno a lo inanimado. En este sentido, el principio del placer no deja de estar al servicio de la pulsión de muerte, en el sentido de que su propia tensión (placer/realidad) permite al organismo dar los rodeos necesarios para cumplir con su propia meta: "el organismo sólo quiere morir a su manera" (Freud 2012, p. 39).

\section{7) El lugar del rodeo (Umweg) en la interpretación derrideana de "Más allá del principio de placer"}

A mi juicio, la clave de la lectura derrideana del problema de la pulsión de muerte en "Más allá del principio de placer" radica en la cuestión del rodeo o desvío (Umweg), traducido al francés como détour. Se trata de una palabra bastante marginal en el texto freudiano, que no aparece más que unas 4 o 5 veces a lo largo de todo el ensayo de 1920. Por ejemplo, leemos:

Durante largo tiempo, quizá, la sustancia viva [lebende Substanz] fue recreada siempre de nuevo y murió con facilidad cada vez, hasta que decisivos influjos externos se alteraron de tal modo que forzaron a la sustancia aún sobreviviente

27 "Sabemos que el principio de placer es propio de un modo de trabajo primario del aparato anímico, desde el comienzo mismo inutilizable, y aun peligroso en alto grado, para la autopreservación del organismo en medio de las dificultades del mundo exterior. Bajo el influjo de las pulsiones de autoconservación del yo, es revelado por el principio de realidad, que, sin resignar el propósito de una ganancia final de placer, exige y consigue posponer [Aufschub] la satisfacción, renunciar a diversas posibilidades de lograrla y tolerar provisionalmente el displacer en el largo rodeo [Umwege] hacia el placer" (Freud 2012, p. $10)$. 
a desviarse más y más [zu immer größeren Ablenkungen] respecto de su camino vital [Lebensweg] originario, y dar unos rodeos [Umwege] más y más complicados, antes de alcanzar la meta de la muerte. Acaso son estos rodeos para llegar a la muerte [Umwege zum Tode], retenidos fielmente por pulsiones conservadoras, los que hoy nos ofrecen el cuadro de los fenómenos vitales (Freud 2012, p. 38).

Aquí Freud señala una observación a partir de la hipótesis especulativa según la cual en el origen de la vida los organismos habrían tenido un rango de vida muy limitado, permaneciendo más tiempo cerca de lo inanimado que de lo animado, razón por la cual la vida tenía que ser "recreada siempre de nuevo", para morir con "facilidad cada vez", como el ciclo de repetición originaria del organismo. Este ciclo originario se habría retenido en las "pulsiones conservadoras", que son, para Freud, efectivamente las pulsiones de muerte, en la medida en que buscan retrotraer al organismo a su estado originario inanimado. Ahora bien, el rodeo, los rodeos, cada vez "más y más complicados", son los que aplazan, posponen o difirieren la consecución de la meta de la vida que es la muerte. Son los rodeos los que han terminado por alterar la temporalidad del organismo vivo y, en un organismo altamente evolucionado como un ser humano, los rodeos son los que acaban por constituir la estructura de la temporalidad de la vida psíquica. Sin los rodeos, un ser humano no sería capaz de proyectar su vida hacia el futuro ni sería capaz de evocar las huellas muertas del pasado.

Ahora bien, Derrida no comprende de la misma manera que Freud la cuestión del rodeo. En "Especular -sobre Freud", radicalizando el aspecto económico de la especulación freudiana (donde "pulsión de muerte" o "pulsión de vida", o "principio del placer" y "principio de realidad" no refieren a cualidades que tengan presencia en el psiquismo, sino que aluden a variaciones cuantitativas de la excitación), el rodeo freudiano será interpretado por Derrida como la instancia a partir de la cual se producen las distribuciones económicas del psiquismo (pulsión de muerte, pulsión de vida o principio del placer y principio de realidad, según sea el caso): "El placer puro y la realidad pura son límites ideales, que es como decir ficciones. Tan destructivas como mortales la una como la otra. Entre las dos, el rodeo difiriente forma pues la efectividad misma del proceso, del proceso 'psíquico' como proceso 'vivo"' (Derrida 2001b, p. 272). Incluso, el mismo fenómeno del psiquismo o vida anímica será un efecto del rodeo, por lo que podemos determinar el Umweg o détour como una instancia anterior a la "presencia a sí de un presente viviente" (Cfr., Derrida 1985), anterior porque efectuante o productiva de la misma: "Tal 'efectividad' [del rodeo] no está pues nunca presente o dada" (Derrida 2001b, p. 272). Es decir, el rodeo ocupa una función estratégica, ya que su movimiento es capaz de constituir la economía de la vida anímica en su totalidad, e inclusive, de su más allá no-viviente: la muerte. El rodeo o desvío (Umweg, détour) pone en juego una elipsis en la descripción del ser viviente en general, y de la vida anímica (o psíquica) en particular, ya que aquello que se nombra como "la pulsión de muerte", surge a partir de un evento excitatorio tan radical -un hecho traumático, por ejemplo- al interior de la economía del ser viviente que no puede sino ser experimentado por el viviente como si se tratase de una fuerza exterior, separándose, imaginariamente, de la misma. Por la no-presencia de la fuerza del rodeo es que entonces la pulsión de muerte se experimenta como si fuera algo esencialmente 
distinto a la pulsión de vida. Así como también el principio del placer se experimenta como siendo un principio esencialmente distinto al principio de realidad (separaciones categoriales que Derrida rechaza al no señalar nada objetivamente determinable). Para Freud, la inclinación mortal del rodeo, por su radicalidad, permanece inconsciente para la vida psíquica pero no deja de ser efectiva en la práctica a través de la autodestructiva compulsión de repetición. He aquí la solidaridad del rodeo (Umweg) freudiano con la lógica de la autoinmunidad, en la medida en que la autoinmunidad puede llegar a poner en juego un desvío (détour) fatal en el orden circular, repetitivo, alternante, de la soberanía democrática; desvío que se produce como resistencia a una amenaza que se alucina externa y a la que debe responderse con violencia, pero que ha surgido del propio marco de la soberanía democrática.

\section{8) Conclusión}

La autoinmunidad no es el mal absoluto de la democracia, sino que también es la condición por la cual la vida democrática se reproduce. Por lo que no se trata de suspender la aporía autoinmunitaria, sino de asumirla. Esta asunción no se logra con una nueva teoría del gobierno que intente purificar a la democracia de su síntoma. Toda la segunda sección de Canallas está abocada a la dilucidación de una respuesta éticopolítica a la exigencia que brota de la ambigüedad de la soberanía democrática. En la medida en que lo autoinmunitario de la democracia expone el cálculo de su soberanía a un devenir incalculable, para bien o para mal, debe exigirse un pensamiento que se enfoque en la dimensión incalculable e incondicional que el horizonte democrático hace posible. De hecho, en Derrida hay algo así como una toma de partido por lo incondicional. Democracia por venir es una manera en que Derrida nombra el partido de la incondicionalidad. Si se quiere ser justo con el otro, y con la venida del otro, cualquiera sea la circunstancia, debe exigirse del pensamiento una responsabilidad que exceda al cálculo de la legalidad del presente.

Podría ser que desplegando una generalización de la lógica del rodeo freudiano podamos re-considerar la tarea planteada por Derrida en Canallas desde una perspectiva lacaniana. Recordemos que el esquema que distingue entre el cálculo de la soberanía y la incondicionalidad de la razón (germen de la responsabilidad) está planteado en clave fenomenológica (Cfr., Derrida 2005, pp. 143-189). En términos generales, lo que yo he querido proponer en esta investigación, como clave de lectura de Canallas, es abordar el tema político a través de un rodeo por el psicoanálisis; no inmediatamente por la fenomenología (Husserl, Lévinas). La instancia elíptica, por decirlo de alguna manera, sobre la que sostengo mi re-consideración podría problematizarse extensamente a través de aquella cita en la que leíamos que: "No debemos disociar nunca la cuestión del deseo y el goce, cuando se trata de lo político, especialmente de lo democrático, del goce consciente o inconsciente, del cálculo o de lo incalculable, a los cuales dan lugar el deseo y el goce" (Derrida 2005, pp. 32-33). Deseo y goce son dos conceptos que Derrida en ninguna parte de Voyous declara explícitamente haber arrancado de la enseñanza de Lacan, pero se trata de dos conceptos que reconfiguran toda la teoría freudiana de las 
pulsiones (Cfr., Braunstein 2013 y la nota 8 de este trabajo), teoría que en sus líneas generales creo haber demostrado como solidaria del esquema autoinmunitario, y que justifican una lectura psicoanalítica del texto derrideano. Ahora bien, tradicionalmente, los conceptos de deseo y goce están asociados, por un lado, a la búsqueda de un bien ausente (el deseo), y por otro, a la satisfacción de un bien presente (goce). Desde este punto de vista tradicional, podríamos enlazar la cuestión del goce con una satisfacción calculable en el marco de la soberanía democrática (el consumo, por ejemplo), y el deseo con la búsqueda de un bien a largo plazo, incluso en un sentido utópico. Pero este punto de vista no plantea problema aporético alguno, ya que lo que la distancia, así planteada, entre el goce y el deseo es apenas el de un lapso de tiempo. El planteamiento lacaniano complejiza el escenario: es el deseo el que está determinado por una ley calculable ${ }^{28}$ (la ley del Padre), mientras que el goce ${ }^{29}$ es lo que está diferido a tal punto que cruza el límite de lo posible: el goce es imposible, y también, incalculable. Por otro lado, es el deseo el que está anclado en el registro de lo simbólico ${ }^{30}$, es decir, ahí donde rige el principio de placer y realidad; en cambio, el goce está anclado más bien en el registro de lo real, lo que implica una peligrosa exposición del sujeto al peligro de perder su lugar en el dominio de lo simbólico: es la muerte, en cierto modo, la pulsión de muerte lo que encripta el concepto de goce. ¿Qué consecuencias guardaría esto para pensar la democracia desde Derrida?

Hay que pensar en el alcance político de la noción de rodeo (Umweg) como la fuerza elíptica al interior de la ley de repetición que subyace a la soberanía democrática y su devenir autoinmunitario. Ahora bien, sostengo que el pensamiento de este Umweg debe recurrir necesariamente a la interpretación política que Derrida hace sobre la teoría freudiana de la pulsión de muerte y de la compulsión de repetición. De este modo se podría llegar a explicar una nueva dimensión psicoanalítica del concepto de lo autoinmunitario, concepto que, como ya hemos visto, da cuenta de un momento de indisociabilidad entre vida y muerte, poder y crueldad, libertad y opresión, en el marco de la "soberanía democrática". Ahora bien, esta dimensión apuntaría a demostrar, en definitiva, que hay una relación ambigua entre el deseo y el goce en la vida democrática, es decir, entre lo que calculadamente se persigue (la autodeterminación popular) y lo que incondicionalmente satisface (la apertura incondicional al otro, a riesgo inclusive de su sacrificio, del sacrificio de la democracia y del otro). Es la promesa de goce el mesianismo $^{31}$ (messianisme) que impulsa la democracia presente más allá de sí misma,

"La Ley hace entrar, así, a la ley del placer en el orden simbólico. La ley del deseo" (Braunstein 2013, p. 33). Ley que en la teoría psicoanalítica de orientación lacaniana es siempre Ley del Padre: "La ley, que separa del goce de la madre y pone al nombre-delPadre en ese lugar, ordena desear" (2013, p. 34).

29 Goce diferido porque prohibido: "El goce está prohibido al que habla como tal. La Ley es fundada por esta prohibición” (Braunstein 2013, p. 32). "El deseo sólo llega a ser deseo por la mediación del orden simbólico que lo constituye como tal" (Braunstein 2013, p. 17). 
hacia su por venir (à venir), mientras que la estructura imposible del goce es aquello que produce paradójicamente el rodeo por lo que llamamos deseo, convirtiendo ese goce en promesa democrática. Un planteamiento ético-político (más que puramente político) de la cuestión, en clave lacaniana y derrideana a la vez, nos llevaría a negociar ${ }^{32}$ entonces esta antinomia de tal manera que sea posible pensar la irresponsabilidad de un deseo expuesto al goce (deseo de un presente expuesto al por venir) tanto como la responsabilidad de un goce (el goce de una "democracia absoluta" si se quiere) que sea capaz de diferirse en el deseo a través de complejos rodeos...

\section{9) Referencias bibliográficas}

Borradori, Giovanna (2003), La filosofía en una época de terror. Diálogos con Jürgen Habermas y Jacques Derrida. Madrid: Taurus.

Braunstein, Néstor A. (2013), El goce. Un concepto lacaniano. Buenos Aires: Siglo XXI Editores.

Contreras Guala, Carlos (2010), Jacques Derrida: Márgenes ético-políticos de la deconstrucción. Santiago de Chile: Editorial Universitaria.

Del Águila, Rafael \& Vallespín, Fernando y otros (2013), La democracia en sus textos. Madrid: Alianza Editorial.

Derrida, Jacques (2012a), "Freud y la escena de la escritura", La escritura y la diferencia. Barcelona: Anthropos Editorial.

(2012b), Espectros de Marx: El estado de la deuda, el trabajo del duelo y la nueva internacional. Madrid: Editorial Trotta.

(2011), Seminario La bestia y el soberano. Volumen II (2002-2003). Buenos Aires: Ediciones Manantial SRL.

(2010), Seminario La bestia y el soberano. Volumen I (2001-2002). Buenos Aires: Ediciones Manantial SRL.

Derrida, Jacques y Roudinesco, Élisabeth (2009), Y mañana, qué. Buenos Aires: Fondo de Cultura Económica.

Derrida, Jacques (2005), Canallas. Dos ensayos sobre la razón. Madrid: Editorial Trotta [Fr. (2003), Voyous. Paris: Galilée].

(2003), El siglo del perdón seguido de Fe y saber. Buenos Aires: Ediciones de la Flor.

(2001a), Estados de ánimo del psicoanálisis. Lo imposible más allá de la soberana crueldad. Buenos Aires: Paidós.

32 Véase, por ejemplo, “El marco de la negociación” en Santos (2014, pp. 329-331). 
(2001b), "Especular -sobre Freud", La tarjeta postal. De Sócrates a Freud y más allá. México D. F.: Siglo XXI Editores [Fr. (1980) La carte postale de Socrate à Freud et au-delà. Paris: Aubier \& Flammarion]. Trotta.

(1997), Mal de archivo. Una impresión freudiana. Madrid: Editorial

(1985), La voz y el fenómeno. Introducción al problema del signo en la fenomenología de Husserl. Valencia: Pre-Textos.

Ferraris, Maurizio (2006), Introducción a Derrida. Buenos Aires: Amorrortu.

Freud, Sigmund (2012), "Más allá del principio de placer (1920)", Obras completas Volumen XVIII. Buenos Aires: Amorrortu Editores [Al. (2001) Gesammelte Werke, bd. 13: Jenseits des Lustprinzips. Massenpsychologie und Ich-Analyse. Das Ich und das Es. Frankfurt: S. Fischer Verlage]

(2011), "El malestar en la cultura (1930 [1929])", Obras completas XXI. Buenos Aires: Amorrortu.

Green, André (2014), ¿Por qué las pulsiones de destrucción o de muerte? Buenos Aires: Amorrortu.

Lacan, Jacques (2011), Seminario 7: La ética del Psicoanálisis (1959-1960). Buenos Aires: Paidós.

(2008), "Kant con Sade", Escritos 2. Buenos Aires: Siglo XXI.

Martínez Ruiz, Rosaura (2013), Freud y Derrida: escritura y psique. México D.F.: Siglo XXI Editores.

Miller, Jacques-Alain (1999), Los signos del goce. Buenos Aires: Paidós.

Negri, Antonio \& Casarino, Cesare (2012), Elogio de lo común. Conservaciones sobre filosofía y politica. Madrid: Paidós.

Santos, Julián (2014), Cuestiones de marco. Estética, política y deconstrucción. Madrid: Escolar y Mayo Editores. 